\title{
Daya Saing Usahatani Tebu terhadap Komoditas Eksisting di Wilayah Kerja Pabrik Gula Wonolangan Kabupaten Probolinggo Tahun 2018
}

\author{
Trikuntari Dianpratiwi*1), Evan Pratama Wibowo'), Heru Wibowo ${ }^{2)}$ \\ ${ }^{1)}$ Pusat Penelitian Perkebunan Gula Indonesia (P3GI), Kota Pasuruan, Jawa Timur \\ ${ }^{2}$ Pabrik Gula Wonolangan, PT. Perkebunan Nusantara XI \\ *Corresponding author: trikuntari.dianpratiwi@gmail.com
}

\begin{abstract}
This study aims to describe in general the performance of Wonolangan Sugar Factory and to analyze the comparison of sugarcane farming with a non-sugarcane commodity in the working area of Wonolangan Sugar Factory. Wonolangan Sugar Factory is located in Probolinggo Regency, almost $90 \%$ of sugarcane raw material is obtained from Lumajang Regency. Commodities that become competitors and the main choice of farmers to be cultivated are rice, maize, and onion. The data used in this study are primary and secondary data. The sampling method used is purposive with in-depth interview technique. Portrait performance of Wonolangan Sugar Factory in the last 5 years is very fluctuating caused by various factors such as climate impacts that are less supportive, the motivation of farmers to grow sugarcane, government policy in the sugar industry. To maintain the smoothness of the mill in the implementation of milling. Wonolangan Sugar Factory has several strategies both on the farm (garden) and off-farm (sugarcane processing at the factory). Based on the comparison of Sugar Business Result (SHU) of sugarcane and non-sugarcane planting pattern, it appears that the analysis shows that sugarcane farming with one Ratoon Cane $(R C)$ category in paddy field can only compete with the pattern of non-cane maize farming throughout the year in South Sugar Factory Wonolangan.
\end{abstract}

Keywords: Competitiveness; Farming; Non-sugarcane; Sugarcane; Wonolangan sugar factory

Cite this as: Dianpratiwi, T., Wibowo, E.P., \& Wibowo, H. 2018. Daya Saing Usahatani Tebu terhadap Komoditas Eksisting di Wilayah Kerja Pabrik Gula Wonolangan Kabupaten Probolinggo Tahun 2018. Caraka Tani: Journal of Sustainable Agriculture. 33(1), 57-67. doi:http://dx.doi.org/10.20961/carakatani.v33i1.19562

\section{PENDAHULUAN}

Tebu pada dasarnya merupakan salah satu komoditas penghasil gula yang patut mendapat perhatian khusus oleh pemerintah. Tebu saat ini bukan menjadi komoditas pilihan utama petani, tetapi komoditas lain seperti padi, jagung, dan bawang merah-lah yang menjadi pilihan utama untuk dibudidayakan. Sebelum diterbitkannya Inpres No. 5 Tahun 1998 (pencabutan Inpres No. 9 Tahun 1975 tentang Tebu Rakyat Intensifikasi), komoditas tebu sangat mudah diperoleh Pabrik Gula (PG) sebagai bahan baku untuk diolah menjadi gula. Sutiarso (2018) dalam penelitiannya mengungkapkan bahwa agribisnis selain tebu terkhusus pada bawang merah di Kabupaten Probolinggo masih dalam kategori menguntungkan dan layak diusahakan, baik secara finansial maupun ekonomi, serta masih memiliki daya saing, baik keunggulan kompetitif maupun keunggulan komparatif.

Minimnya perhatian dan proteksi ketat dari pemerintah terhadap komoditas tebu seperti pendistribusian pupuk, adanya Harga Eceran Tertinggi (HET) gula, dan kredit usaha tani yang semakin rumit juga mempengaruhi daya saing usahatani tebu. Hal tersebut tentunya berpengaruh pada penurunan produksi dan produktivitas tebu, khususnya di sentra produksi tebu di Jawa yang pada akhirnya berdampak juga adanya pergeseran pengusahaan tebu dari lahan sawah ke lahan kering (Soentoro et al., 1999).

Produktivitas tebu dipengaruhi oleh berbagai faktor, tidak hanya tipe lahan (sawah atau tegalan) tetapi juga penggunaan sarana produksi dan teknik budidaya. Sebagai contoh, produktivitas tebu di Kabupaten Madiun dan Kediri pada lahan sawah dan tanam awal cenderung lebih rendah dibandingkan di lahan tegalan dan sebaliknya 
untuk tebu keprasan. Sementara produktivitas tebu di lahan sawah Kabupaten Malang dan Jember relatif lebih tinggi daripada di lahan tegalan. Namun rendemen yang diperoleh petani antar kabupaten relatif sama, berkisar 6,0 - 6,8\% dengan pola bagi hasil petani rata-rata $66 \%$. Potensi usahatani tebu lahan kering di pulau Jawa masih dapat ditingkatkan produktivitasnya melalui perbaikan manajemen usahatani yang diikuti oleh kebijakan pemerintah terhadap insentif harga gula dan penyediaan kredit usahatani. Di sisi lain Pulau Jawa juga merupakan sentra produksi beras, sehingga akan bersaing ketat dalam pemanfaatan lahan yang ada. Keuntungan usahatani tebu secara ekonomi dapat dipandang sebagai cerminan efisiensi ekonomi suatu usaha. Usahatani tebu di Kabupaten Madiun dan Kabupaten Kediri tidak mempunyai keunggulan komparatif sedangkan di Kabupaten Malang dan Jember menunjukkan keunggulan komparatif (Ariani et al., 2004).

Pabrik Gula Wonolangan merupakan salah satu pabrik yang terletak di Kabupaten Probolinggo dan sangat berdekatan dengan pabrik se-saudaranya di lingkup PG-PG di PTPN XI. Pabrik yang berbatasan dengan PG Wonolangan diantaranya: (1) Bagian Selatan: PG Jatiroto (Kabupaten Lumajang), (2) Bagian Barat: PG Kedawung (Kabupaten Pasuruan), dan (3) Bagian Timur: PG Gending dan PG Pajarakan (Kabupaten Probolinggo). Keseluruhan PG tersebut masih aktif dalam memproduksi gula. Tidak mudah mendapatkan bahan baku tebu untuk setiap tahun masa giling PG tersebut. Persaingan dengan PG-PG di sekitarnya dan persaingan dengan komoditas non-tebu menjadi tantangan yang kuat bagi PG Wonolangan. Salah satu cara yang ditempuh adalah bentuk kemitraan yang diterapkan membuat Pabrik Gula memberikan segala kemudahan kepada petani agar mudah mendapatkan fasilitas seperti bibit, pupuk dan sistem pengangkutan tebu ke pabrik gula. Hal ini dilakukan untuk menjamin seluruh kegiatan penanaman tebu berjalan lancar (Maulidiah, 2012).

Oleh sebab itu sebagai salah satu contoh, pengembangan tebu di Kabupaten Lampung Utara dilakukan dengan beberapa strategi antara lain: a) Mengembangkan potensi lahan usahatani tebu yang ada (eksisting), b) Melakukan penyuluhan proses pengolahan produk sampingan tebu agar optimal untuk tambahan pendapatan petani dan menambah luas lahan untuk budidaya tebu, c) Membangun kemitraan dengan PG dan menetapkan program yang mendukung peningkatan produksi tebu seperti program bantuan sarana produksi untuk petani tebu (Ahadis et al., 2012).

Pemilihan lokasi di wilayah kerja PG Wonolangan memiliki beberapa argumen diantaranya: 1) Salah satu pabrik gula yang memiliki wilayah kerja Kabupaten Lumajang dan Kabupaten Probolinggo, 2) Meskipun wilayah kerja PG Wonolangan terhimpit tetapi tetap memiliki posisi tawar yang tinggi, 3) Belum adanya penelitian mengenai daya saing usahatani tebu di wilayah kerja PG Wonolangan, dan 4) Terdiri dari beberapa komoditas non-tebu yang menjadi pesaing yaitu bawang merah, padi, dan jagung. Maka dari itu, perlu adanya kajian lebih lanjut mengenai daya saing usahatani tebu dengan komoditas eksisting di wilayah kerja PG Wonolangan.

Penelitian ini bertujuan untuk mendeskripsikan secara umum kinerja PG Wonolangan di Industri Pergulaan Nasional dan menganalisis perbandingan usahatani tebu dengan komoditas non-tebu di wilayah kerja PG Wonolangan. Manfaat penelitian ini adalah untuk memberikan masukan untuk pembuat kebijakan baik di lingkup PG Wonolangan dan PTPN XI, maupun pihak pemerintah (Kementerian BUMN) untuk mengelola dan mengembangkan PG Wonolangan serta usahatani tebu rakyat di wilayah PG tersebut.

\section{METODE PENELITIAN}

\section{Tempat dan Waktu Penelitian}

Penelitian ini dilaksanakan secara sengaja pada bulan Maret 2018 di Wilayah Kerja PG Wonolangan yaitu di Kabupaten Probolinggo dan Kabupaten Lumajang. Lokasi penelitian dibagi menjadi 3 wilayah, yaitu wilayah Timur, wilayah Barat, dan wilayah Selatan. Sampel kebun dipilih secara sengaja dengan pertimbangan mampu mewakili seluruh kondisi wilayah kerja PG Wonolangan. Wilayah tersebut meliputi:

1. Wilayah Barat : Desa Banjarsari dan Desa Tongas Wetan

2. Wilayah Timur : Desa Dringu, Desa Sumber Kedung, dan Desa Sumendi

3. Wilayah Selatan : Desa Triwung Lor dan Desa Salak 


\section{Metode Pengumpulan Data}

Penelitian ini dilaksanakan menggunakan metode survei. Menurut Singarimbun (1989) penelitian survei adalah penelitian yang mengambil sampel dari satu populasi dan menggunakan kuesioner sebagai alat pengumpulan data yang pokok. Teknik penentuan informan dalam penelitian ini secara sengaja (Purposive Sampling) dengan kriteria petani yang merupakan tokoh pertanian, mempunyai pengalaman berusahatani cukup panjang, dapat memberikan informasi yang dibutuhkan, baik di wilayah masing-masing tebu maupun non-tebu.

Data yang dikumpulkan meliputi data primer dan sekunder. Data primer terdiri atas data usahatani non-tebu (jagung, bawang merah, kedelai, dan padi yang diperoleh dari hasil wawancara kepada petani non-tebu) dan data usahatani tebu. Data sekunder meliputi data lima tahun terakhir potret kinerja Pabrik Gula Wonolangan, data laba rugi Tebu Sendiri (milik PG) per kebun MT 2016/2017 kategori Plant Cane dan Ratoon Cane di lahan sawah dan tegal, Rencana Strategi berdasarkan Rapat Kerja Monitoring dan Evaluasi PG Wonolangan bulan Februari 2018 yang semuanya diperoleh dari PG Wonolangan.

\section{Teknik Analisis Data}

1. Deskriptif Kualitatif

Penelitian ini menggunakan metode deskriptif kualitatif. Moleong (2008) menjelaskan bahwa penelitian deskriptif yaitu penelitian yang menggambarkan dan melukiskan keadaan obyek penelitian pada saat sekarang sebagaimana adanya berdasarkan fakta-fakta. Penelitian ini merupakan usaha untuk mengungkapkan masalah atau keadaan atau peristiwa sebagaimana adanya sehingga hanya bersifat sebagai pengungkap fakta. Hasil penelitian ditekankan untuk memberikan gambaran secara obyektif tentang keadaan yang sebenarnya dari obyek yang diteliti. Tujuan deskriptif kualitatif dalam penelitian ini yaitu untuk memberikan gambaran secara sistematis, faktual dan akurat mengenai faktafakta penelitian. Fakta-fakta tersebut yaitu tentang kinerja PG Wonolangan dan respon petani terhadap komoditas yang dibudidayakan. Besarnya pengaruh rendemen terhadap peluang petani menjalankan usahatani tebu sesuai pilihan kelembagaan yang ada maka sangat diperlukan upaya untuk meningkatkan rendemen baik dari aspek manajemen penentu (pengambil keputusan) maupun aspek pelaksanaan usahatani dan efisiensi PG (Priyadi, 1997).

2. Analisis Usaha

Tujuan dilakukan analisis usaha adalah melihat alokasi pengeluaran kegiatan usahatani bisa dijangkau oleh penerimaan sehingga pendapatan dapat dimaksimalkan. Untuk melakukan pendekatan tersebut dilakukan pengambilan teknis budidaya yang diterapkan di lahan tersebut dan rincian biaya yang akan dialokasikan, untuk dilakukan analisis usahatani. Kebutuhan biaya pada masing-masing pekerjaan diestimasikan dalam bentuk biaya pekerjaan secara rinci pada masing-masing tahap pekerjaan budidaya tebu. Biaya lain terkait usahatani tebu seperti tenaga kerja, biaya tebang, muat dan angkut didapatkan dengan melakukan survei biaya wajar di sekitar wilayah yang dikaji. Banyak penelitian usahatani tebu menunjukkan bahwa keuntungan yang diperoleh petani sesuai dengan upaya yang dilakukan menjadi faktor penentu luas tanam tebu. Maka sulit diharapkan perluasan tanaman tebu tanpa upaya membangun sistem pergulaan yang menguntungkan petani tebu. Untuk memanfaatkan potensi on farm tebu yang sangat besar diperlukan langkah strategis antara lain perbaikan kinerja pabrik, perbaikan skala usahatani dan sistem pembiayaan (Bantacut, 2010).

Berdasarkan informasi teknis dan tingkat harga, dilakukan identifikasi unsur-unsur manfaat dan biaya yang timbul pada budidaya tebu yang dilakukan pada lahan tersebut. Dengan menggunakan hasil identifikasi unsur biaya serta informasi harga yang relevan, maka ekspektasi nilai arus penerimaan dan arus biaya usaha budidaya dapat diidentifikasi. Arus penerimaan merupakan arus nilai produk utama dan produk ikutannya, dalam hal ini produk utama adalah gula dan produk ikutan adalah tetes. Sedangkan arus biaya merupakan arus nilai pengeluaran baik untuk investasi maupun untuk operasional kegiatan produksi. 


\section{HASIL DAN PEMBAHASAN}

\section{Potret Kinerja PG Wonolangan}

PG Wonolangan merupakan salah satu pabrik gula yang berada di bawah naungan PT. Perkebunan Nusantara XI dengan core bussiness adalah produksi gula. PG Wonolangan dalam memasok kebutuhan giling tiap tahunnya mengambil dari tebu rakyat (TR) petani. Sekitar 90\% pasokan tebu berasal dari TR dan $10 \%$ sisanya berasal dari tebu sendiri (TS). Dengan komposisi pasok tebu rakyat yang tinggi, pihak manajemen PG Wonolangan melakukan sistem bermitra dengan petani agar memenuhi kebutuhan pasoknya dalam masa giling. Kemitraan antara petani tebu dan pabrik gula bermula sejak pabrik gula kekurangan pasokan bahan baku tebu dan menggiling tebu dibawah kapasitas giling, sedangkan petani tidak memiliki jaminan pasar dan membutuhkan pengolahan lebih lanjut agar tebu lebih bernilai. Dengan demikian, terdapat hubungan saling membutuhkan antara pabrik gula dan petani tebu rakyat (Maulidia, 2012). Untuk melihat lebih rinci produksi TR dan TS serta kinerja Pabrik Gula Wonolangan adalah sebagai berikut:

Tabel 1. Kinerja PG Wonolangan Tahun 2013 - 2017

\begin{tabular}{|c|c|c|c|c|c|c|c|c|}
\hline \multirow[t]{2}{*}{ Kategori } & \multirow[t]{2}{*}{ Tahun } & \multirow{2}{*}{$\begin{array}{l}\text { Luas Lahan } \\
\text { (ha) }\end{array}$} & \multirow{2}{*}{$\begin{array}{l}\text { Produktivitas } \\
\quad \text { (ton/ha) }\end{array}$} & \multirow{2}{*}{$\begin{array}{l}\text { Produksi } \\
\text { Tebu } \\
\text { (ton) }\end{array}$} & \multirow{2}{*}{$\begin{array}{c}\text { Rendemen } \\
(\%)\end{array}$} & \multirow{2}{*}{$\begin{array}{c}\text { Total Gula yang } \\
\text { dihasilkan } \\
\text { (ton) }\end{array}$} & \multicolumn{2}{|c|}{$\begin{array}{l}\text { Kap. Giling } \\
\text { (ton/hari) }\end{array}$} \\
\hline & & & & & & & KES & KIS \\
\hline \multirow[t]{5}{*}{ TR } & 2013 & $4.102,78$ & 67.02 & $274.956,4$ & 6,79 & $18.668,13$ & $1.856,40$ & $1.677,90$ \\
\hline & 2014 & $3.772,56$ & 64.20 & $242.213,6$ & 7,50 & $18.154,78$ & $1.820,40$ & $1.651,60$ \\
\hline & 2015 & $4.219,03$ & 60.80 & $256.503,5$ & 8,59 & $22.045,40$ & $1.867,60$ & $1.800,30$ \\
\hline & 2016 & $3.372,24$ & 70.93 & $239.198,6$ & 5,99 & $14.331,50$ & $1.859,20$ & $1.693,50$ \\
\hline & 2017 & $2.342,30$ & 81.71 & $191.378,8$ & 7,07 & $13.527,04$ & $1.972,50$ & $1.777,50$ \\
\hline \multicolumn{2}{|c|}{ Rata-Rata } & $3.561,78$ & 67,62 & $240.850,2$ & 7,20 & $17.345,37$ & $1.875,22$ & $1.720,16$ \\
\hline \multirow[t]{5}{*}{ TS } & 2013 & 398,25 & 60,08 & $23.928,20$ & 7,89 & $1.887,37$ & $1.856,40$ & $1.677,90$ \\
\hline & 2014 & 303,93 & 48,56 & $14.757,90$ & 8,79 & $1.297,12$ & $1.820,40$ & $1.651,60$ \\
\hline & 2015 & 208,68 & 61,30 & $12.791,20$ & 9,69 & $1.239,50$ & $1.867,60$ & $1.800,30$ \\
\hline & 2016 & & & $5.932,60$ & 6,58 & 390,49 & $1.859,20$ & $1.693,50$ \\
\hline & 2017 & 386,32 & 88,66 & $34.250,17$ & 8,66 & $2.967,18$ & $1.972,50$ & $1.777,50$ \\
\hline \multicolumn{2}{|c|}{ Rata-Rata } & 271,06 & 67,63 & $18.332,01$ & 8,49 & $1.556,33$ & $1.875,22$ & $1.720,16$ \\
\hline \multirow[t]{5}{*}{$\mathrm{TS}+\mathrm{TR}$} & 2013 & $4.501,03$ & 66,40 & $298.884,60$ & 6,88 & $20.555,50$ & $1.856,40$ & $1.677,90$ \\
\hline & 2014 & $4.076,49$ & 63,04 & $256.971,50$ & 7,57 & $19.451,90$ & $1.820,40$ & $1.651,60$ \\
\hline & 2015 & $4.427,69$ & 60,82 & $269.294,70$ & 8,65 & $23.284,90$ & $1.867,60$ & $1.800,30$ \\
\hline & 2016 & $3.430,35$ & 71,46 & $245.131,20$ & 6,01 & $14.721,99$ & $1.859,20$ & $1.693,50$ \\
\hline & 2017 & $2.728,62$ & 82,69 & $225.628,92$ & 7,31 & $16.494,21$ & $1.972,50$ & $1.777,50$ \\
\hline \multicolumn{2}{|c|}{ Rata-Rata } & $4.335,07$ & 63,45 & $275.050,27$ & 7,67 & $21.097,43$ & $1.875,22$ & $1.720,16$ \\
\hline
\end{tabular}

Sumber: Data Sekunder PG Wonolangan (2018) diolah.

Berdasarkan Tabel 1, tampak bahwa luas lahan tebu rakyat di wilayah PG Wonolangan senantiasa mengalami penurunan dari tahun 2015 hingga 2017, hal tersebut karena banyak petani beralih budidaya ke komoditas lain. Berdasarkan data BPS yang menjadi pesaing komoditas tebu adalah bawang merah, padi, dan jagung. Luas panen masing-masing komoditas pesaing di kabupaten probolinggo adalah bawang merah (5.529 ha), padi (66.657 ha) dan jagung (59.859 ha). Sedangkan tebu sendiri hanya memliki luas panen hanya sebesar 4.019 ha (BPS, 2017). Fluktuatif lahan tebu tersebut disebabkan banyak petani yang beralih ke komoditas lain. Dari sisi produksi mengalami penurunan dikarenakan terkena dampak el nino di tahun 2017. Secara tidak langsung, bobot tebu berkurang, namun dampak el nino juga berdampak positif pada rendemen yang dihasilkan, ditunjukkan dengan rendemen meningkat 1,3\% pada tahun 2017.

Selain dari sisi luas dan produksi, komoditas tebu juga belum mampu bersaing dengan bawang merah, jagung, dan padi. Berdasarkan data BPS menunjukkan padi mampu memiliki tingkat produktivitas 5,45 ton/ha, jagung 4,33 ton/ha, dan bawang merah paling tinggi hingga 7,27 ton/ha. Ketiga komoditas tersebut bisa menghasilkan hingga 2-3 kali panen dalam satu tahun. Dimungkinkan produksi tebu belum bisa bersaing dipengaruhi oleh faktor iklim, fasilitasi sarana produksi dan pengaruh lingkungan sosial yang mayoritas petani Probolinggo menanam tanaman 
pangan dan hortikultura. Sehingga banyak petani yang enggan menanam tebu atau tetap menanam tanaman yang biasa ditanam (non-tebu).

Pada saat ini fasilitas pupuk sebagai sarana produksi sangat sulit diperoleh oleh petani dikarenakan kebijakan pemerintah yang membatasi distribusi pupuk kalangan petani tebu. Menurut Tunjungsari (2014) mengemukakan bahwa pupuk memiliki pengaruh yang positif terhadap produksi tebu sampai dengan batas tertentu. Pemupukan yang sesuai akan meningkatkan jumlah produksi tebu per satuan luas lahan. Oleh sebab itu, sarana produksi seperti pupuk juga harus dipertimbangkan pemerintah agar petani tidak enggan dalam budidaya tebu.

Selain faktor pupuk, pemeliharaan sifat fisik tanah juga berpengaruh terhadap produktivitas tebu. Sifat fisik tanah yang baik akan mendukung berbagai proses penting di dalam tanah, seperti kehidupan organisme dalam tanah untuk pertumbuhan tanaman. Kelangkaan air sering menjadi kendala atau pembatas usahatani dalam pengelolaan lahan kering. Oleh karena itu, inovasi teknologi pengelolaan air dan iklim sangat diperlukan, meliputi irigasi suplemen, prediksi iklim serta pemetaan masa tanam dan pola tanam (Prihatiningrum, 2010).

Usaha agar pasokan tebu bisa tetap stabil maka seharusnya setap pabrik gula memiliki strategi baik di on farm maupun off farm. Menurut Prawiro (2011) untuk mendukung peningkatan produksi gula di Jawa Timur telah dilakukan berbagai kegiatan, baik di sektor on farm maupun off farm. Secara garis besar perbaikan sektor on farm dilakukan melalui penyediaan sarana produksi, bibit unggul, penerapan standar baku budidaya, rehabilitasi tanaman melalui bongkar ratoon dan rawat ratoon, precision farming, dan lain-lain. Sementara di sektor off farm dilakukan peningkatan kapasitas giling dan rehabilitasi pabrik. Kegiatan perbaikan on farm yang cukup nyata pengaruhnya di Jawa Timur adalah bongkar ratoon. Tanaman yang sudah dikepras lebih dari 3 kali dibongkar dan diganti dengan varietas tebu unggul baru. Penggantian ini disertai dengan upaya pemupukan dalam dosis, komposisi dan waktu yang tepat, pengairan dan perawatan lainnya, sesuai dengan baku teknis. Bibit ditanam berjenjang dengan luasan sesuai kebutuhan dan pelaksanaan pembangunan melibatkan petani (Koperasi Petani Tebu Rayat) dan PG Maka dari itu, PG Wonolangan juga memiliki beberapa strategi yang ditempuh baik on farm maupun off farm pada musim giling 2018, diantaranya:

1. Strategi On Farm:

a. Menambah areal tebu di area perkebunan swasta yang berada di sekitar PG Wonolangan, antara lain: a) Area milik PT. LBM Lokasi di Bentar Probolinggo dengan potensi perluasan tahun 2018 seluas 100 ha, tahun 2019 seluas 300 ha, b) Areal milik perkebunan Gunung Ringgit dengan potensi perluasan 75 ha, c) Areal milik Pemerintah Kota Probolinggo dengan potensi perluasan 2 ha, d) Areal milik perkebunan PT. Kalijeruk dengan potensi perluasan sebesar 100 ha, e) Perluasan daerah Triwung Lor yang saat ini didominasi komoditas jagung dengan potensi perluasan 200 ha.

b. Peningkatan Produktivitas TR dan TS dengan sasaran protas minimal 800 kuintal/ha dan protas TS minimal 900 kuintal/ha dengan langkah sebagai beikut: a) Pemberian blotong ke kebun TS maupun TR secara gratis, b) Pemberian pupuk maksimal sesuai dengan rekomendasi dosis, c) Mengupayakan pemberian air secara maksimal dengan memanfaakan sumber-sumber air yang ada

c. Penebangan tepat waktu sesuai jadwal dengan kualitas MBS (Manis, Bersih, Segar) dengan sosialisasi melalui Forum Temu Kemitraan Wilayah (FTK-W) dengan strategi antara lain: a) Mapping wilayah dan petani bagi petugas PG, b) Pembinaan dan pengawalan secara intensif, c) Pelayanan Prima, d) Pemasangan patok tebang, e) Kontrak tenaga tebang $130 \%$ dari kapasitas harian, f) Tebang "Plontos" (bersih dari akar, daun, sogolan atau tebu muda)

\section{Strategi Off Farm:}

Masalah inefisiensi PG membentang dari sisi budidaya (on farm) yaitu produktivitas tebu yang rendah dan kualitas panen tebu yang tidak sesuai dengan kriteria MBS, sampai kepada sisi pabrik (off farm) yaitu biaya produksi gula di pabrik yang belum mencapai posisi ekonomis karena penggunaan bahan bakar yang tidak efisien. Dikatakan tidak efisien karena ampas yang dihasilkan dalam proses penggilingan tebu tidak mencukupi sebagai bahan bakar sehingga harus disuplesi dengan bakan bakar yang lain, masalah 
rendemen, biaya perawatan pabrik yang tinggi, rendahnya produktivitas tenaga kerja dan terbatasnya nilai tambah produk (Ahmad et al., 2016). Maka PG Wonolangan membangun strategi di sisi off farm dengan langkahlangkah sebagai berikut:

1) Peningkatan kapasitas giling melalui: a) Pergantian Drum Buyer KTR No. 3 dan 5 Ex PG Gending, b) Penggantian Penggerak Gilingan 2, c) Relokasi Evaporator LP 1400 Ex PG Kanigoro, d) Relokasi Pan Masak A dan D Ex PG Kanigoro, e) Relokasi Putaran Low Grade Ex PG Kanigoro dan PG Asembagus.

2) Penurunan kehilangan POL (Efisiensi Pabrik) melalui: a) Modifikasi Pisau Cane Knife dan Unigrator untuk menaikkan effisiensi gilingan (Preparation Index), b) Relokasi Rotary Vacum Vilter Ex PG Semboro, c) Pemasangan Chiller untuk air pendingin palung $\mathrm{D}$, d) Pengadaan pompa vacum kap $5500 \mathrm{~m}^{3} / \mathrm{jam}$, e) Pembuatan Spray Pond Kap $500 \mathrm{~m}^{3} / \mathrm{jam}$.

3) Peningkatan kualitas produk melalui: a) Pemasangan saringan vibro di gilingan, b) Redesain defaktor dan bejana sulfitir, c) Redesain Single Tray untuk penegendapan nira, penambahan ketinggian level feed launder, d) Pembuatan sulfur melter, e) Pembuatan remelter, f) Pembuatan cyclone debu gula.

Pabrik Gula dalam berbagai keterbatasan telah melakukan upaya untuk memperbaiki kinerja, tetapi mengalami berbagai kendala, antara lain:
1. Kesulitan memperloleh lahan

2. Pengembangan lahan tebu ke lahan kering sehingga biaya angkut tebu meningkat, karena lokasi lahan kering pada umumnya jauh dari Pabrik Gula sehingga membutuhkan biaya angkut lebih tinggi

3. Jumlah produksi gula kurang dari 250.000 kuintal per tahun, sehingga harga pokok produksi mahal (tidak bersaing)

4. Mutu bahan baku (tebu) belum optimal sehingga biaya produksi PG tidak efisien

5. Kapasitas giling PG rendah (di bawah 2.000 Ton Cane per Day) (Bantacut, 2010).

\section{Analisis Daya Saing Usaha}

1. Analisis Usahatani Non-Tebu

Secara umum, usahatani non-tebu di wilayah kajian memliki variasi komoditas yang dibudidayakan. Setiap komoditas yang dibudidayakan memiliki nilai sisa hasil usaha (SHU) yang bervariatif pula tergantung dari pendapatan dan biaya yang dikeluarkan. Menurut Nurjayanti dan Naim (2014), komponen biaya usahatani terdiri dari biaya tetap dan biaya variabel, dimana pada penelitian ini biaya tetap adalah biaya sewa lahan, sedangkan biaya variabel meliputi biaya tenaga kerja, dan biaya bahan (pupuk, herbisida, dan sebagainya). Pada segi pendapatan diperoleh melalui hasil produksi usahatani non-tebu dikalikan harga jual. Maka dari itu, berikut kami sajikan produksi usahatani non-tebu per hektar per musim.

Tabel 2. Produksi Usahatani Non-Tebu per hektar per musim

\begin{tabular}{ccccrrrr}
\hline No. & Desa & Komoditas & $\begin{array}{c}\text { Produktivitas } \\
\text { (ton/ha) }\end{array}$ & $\begin{array}{c}\text { Biaya } \\
(\mathrm{Rp})\end{array}$ & $\begin{array}{c}\text { Pendapatan } \\
(\mathrm{Rp})\end{array}$ & \multicolumn{1}{c}{$\begin{array}{c}\text { SHU/musim } \\
(\mathrm{Rp})\end{array}$} & $\begin{array}{c}\text { Persentase SHU } \\
(\%)\end{array}$ \\
\hline 1. & Wilayah & Jagung & 4,45 & 11.419 .575 & 17.800 .000 & 6.738 .475 & 59,01 \\
& Timur & Padi & 4,8 & 11.885 .025 & 24.000 .000 & 12.114 .975 & 101,93 \\
& & Bawang Merah & 1,5 & 22.778 .963 & 25.500 .000 & 2.721 .038 & 11,95 \\
& & Kedelai & 1,6 & 8.533 .250 & 10.400 .000 & 2.425 .000 & 28,42 \\
\hline 2. & Wilayah & Padi & 5,3 & 10.895 .275 & 25.440 .000 & 14.544 .725 & 133,5 \\
& Barat & Jagung & 4,13 & 9.511 .972 & 16.200 .000 & 6.688 .028 & 70,31 \\
\hline 3. & Wilayah & Padi & 4,95 & 10.551 .983 & 23.760 .000 & 13.208 .017 & 125,17 \\
& Selatan & Jagung & 5,07 & 12.653 .344 & 19.920 .000 & 7.266 .656 & 57,43 \\
\hline
\end{tabular}

Sumber: Analisis Data Primer, 2018

Komoditas non-tebu yang terdapat di desa sampel adalah padi, jagung, bawang merah, dan kedelai. Produktivitas padi antara 4,8 - 5,3 ton/ha dengan SHU antara Rp 12.114.975,-- hingga $\mathrm{Rp}$ 14.544.725,-/ha dan persentase SHU antara 101,93 - 133,5\%. Produktivitas jagung berkisar antara 4.13 - 5.07 ton/ha dengan SHU berkisar antara Rp 6.688.028,- 
hingga Rp 7.266.656,-/ha dan persentase SHU antara $57,43-70,31 \%$. Produktivitas bawang merah 1,5 ton/ha dengan SHU Rp 2.721.038,/ha, dan persentase SHU sebesar 11,95\%. Produktivitas kedelai 1,6 ton/ha dengan SHU Rp 2.425.000,-/ha, dan persentase SHU sebesar $28,42 \%$. Semua tanaman non-tebu di 3 wilayah sampel (padi, kedelai, jagung, dan bawang merah) mempunyai persentase SHU positif yang menunjukkan bahwa semuanya mengalami keuntungan dalam usahatani komoditas non-tebu. Tampak bahwa usahatani padi dan jagung dapat memberikan SHU dengan nilai besar, namun perlu diketahui bahwa usahatani tersebut juga membutuhkan modal yang besar terutama perawatan, rawan dalam gagal panen, dan harga jual yang berfluktuatif.
2. Analisis Usahatani Tebu di Wilayah Kerja PG Wonolangan

Usahatani tebu terdiri dari 2 kategori tanaman yaitu Plant Cane (Tanaman Awal) dan Ratoon Cane (Tanaman Keprasan) baik pada lahan sawah maupun tegal. Tebu membutuhkan waktu panen hingga 1 tahun, jadi dalam satu tahun petani hanya bisa menanam tebu saja. Hasil secara kualitas maupun kuantitas pada masing kategori tanaman juga berbeda-beda. Maka dari itu, SHU dalam usahatani tebu juga berbeda-beda setiap kategori tanaman baik tegal maupun sawah. Beikut tabel analisis usahatani tebu di masing-masing PG Wonolangan:

Tabel 3. Analisis Usahatani Tebu di Wilayah Kerja Bagian Timur PG Wonolangan.

\begin{tabular}{clrr}
\hline \multicolumn{1}{c}{ Noraian } & Slant Cane & & Satoon Cane \\
\hline N. & Produksi Tebu (ton/ha) & 103 & 85,6 \\
2. & Rendemen (\%) & 7,26 & 7,78 \\
3. & Bagi Hasil Gula Tani (66\%) & 4,94 & 4,40 \\
4. & Bagi Hasil Tetes (3\% tebu) & 3,09 & 2,57 \\
5. & Harga Gula (Rp ,-/ton) & 10.500 .000 & 10.500 .000 \\
6. & Harga Tetes (Rp ,-/ton) & 1.800 .000 & 1.800 .000 \\
7. & Biaya (Rp) & 48.243 .895 & 39.301 .224 \\
8. & Pendapatan & & \\
& Gula Tani (Rp) & 51.821 .154 & 46.151 .582 \\
& Tetes Tani (Rp) & 5.562 .000 & 4.622 .400 \\
& Jumlah Pendapatan (Rp) & 57.383 .154 & 50.773 .982 \\
9. & Hasil Usahatani (Rp) & 9.139 .259 & 11.472 .759 \\
10. & Persentase Usaha (\%) & 18,94 & 29,19 \\
\hline
\end{tabular}

Sumber Analisis Data Primer, 2018

Tabel 3 menunjukkan usahatani tebu desa sampel wilayah Timur secara ekonomi memiliki persentase SHU positif di semua kategori, baik Plant Cane (PC) dan Ratoon Cane (RC) di lahan sawah yang berarti usahatani tebu di desa sampel wilayah Timur juga mempunyai prospek yang menguntungkan di lahan sawah pada PC maupun RC. Namun jika dibandingkan antar kategori maka persentase SHU tertinggi diperoleh pada kategori RC di lahan sawah yaitu 29,19\%, sedangkan terendah adalah persentase SHU pada kategori PC di lahan sawah. Hal ini disebabkan biaya yang dibutuhkan pada RC lebih rendah daripada PC meskipun terdapat penurunan produktivitas pada RC, sedangkan pada PC lahan tegal dibutuhkan biaya bibit dan pengolahan lahan. Kisaran persentase SHU usahatani tebu di desa sampel wilayah Timur adalah 18,94 - 29,19\% dengan nilai SHU antara Rp 9,1 juta hingga Rp 11,4 juta per hektar per musim tanam. Biaya berpengaruh signifikan terhadap pendapatan petani tebu, ini menunjukkan bahwa dengan biaya yang tinggi yaitu sewa lahan, bibit, pupuk, herbisida, tenaga kerja, dan produktivitas tinggi dapat memaksimalkan pendapatan petani dari usahatani tebu (Sutrisno, 2009). 
Tabel 4. Analisis Usahatani Tebu di Wilayah Kerja Bagian Barat PG Wonolangan.

\begin{tabular}{clrrrr}
\hline \multirow{2}{*}{ No. } & \multicolumn{1}{c}{ Uraian } & \multicolumn{2}{c}{ Sawah } & \multicolumn{2}{c}{ Tegal } \\
& Plant Cane & Ratoon Cane & Plant Cane & Ratoon Cane \\
\hline 1. & Produksi Tebu (ton/ha) & 106,9 & 69,4 & 70,4 & 70,4 \\
2. & Rendemen (\%) & 7,05 & 7,78 & 8,44 & 8,44 \\
3. & Bagi Hasil Gula Tani (66\%) & 4,97 & 3,56 & 3,92 & 3,92 \\
4. & Bagi Hasil Tetes (3\% tebu) & 3,21 & 2,08 & 2,11 & 2,11 \\
5. & Harga Gula (Rp, ,-lton) & 10.500 .000 & 10.500 .000 & 10.500 .000 & 10.500 .000 \\
6. & Harga Tetes (Rp,-/ton) & 1.800 .000 & 1.800 .000 & 1.800 .000 & 1.800 .000 \\
7. Biaya (Rp) & 52.749 .153 & 34.990 .146 & 38.998 .150 & 29.903 .150 \\
8. & Pendapatan & & & & \\
& Gula Tani (Rp) & 52.227 .599 & 37.417 .288 & 41.176 .397 & 41.176 .397 \\
& Tetes Tani (Rp) & 5.772 .600 & 3.747 .600 & 3.801 .600 & 3.801 .600 \\
& Jumlah Pendapatan (Rp) & 58.000 .199 & 41.164 .888 & 44.977 .997 & 44.977 .997 \\
9. & Hasil Usahatani (Rp) & 5.251 .046 & 6.174 .741 & 5.979 .847 & 15.074 .847 \\
10. & Persentase Usaha (\%) & 9,95 & 17,65 & 15,33 & 50,41 \\
\hline Sumb
\end{tabular}

Sumber: Analisis Data Primer, 2018

Tabel 4 menunjukkan persentase SHU desa sampel wilayah Barat yang sama dengan desa sampel wilayah Timur. Secara ekonomi usahatani tebu memiliki persentase SHU positif di semua kategori (PC dan RC di lahan sawah serta PC dan RC di lahan tegalan), yang berarti usahatani tebu di desa sampel wilayah Barat juga mempunyai prospek yang menguntungkan baik di lahan sawah maupun tegalan pada PC maupun RC. Namun jika dibandingkan antar kategori maka persentase SHU tertinggi diperoleh pada kategori RC di lahan tegal yaitu $50,41 \%$, sedangkan terendah adalah persentase SHU pada kategori PC di lahan sawah yaitu 9,95\%. Hal ini disebabkan biaya yang dibutuhkan pada RC lebih rendah daripada PC meskipun terdapat penurunan produktivitas pada RC tegal. Sedangkan pada PC lahan sawah dibutuhkan biaya bibit dan pengolahan lahan, serta biaya sewa lahan sawah yang sangat mahal. Kisaran persentase SHU usahatani tebu di desa sampel bagian barat adalah 9,95-50,41\% dengan nilai SHU antara Rp 5 juta hingga Rp 15 juta per hektar per musim tanam.

Tabel 5. Analisis Usahatani Tebu di Wilayah Kerja Bagian Selatan PG Wonolangan.

\begin{tabular}{|c|c|c|c|c|c|}
\hline \multirow{2}{*}{ No. } & \multirow{2}{*}{ Uraian } & \multicolumn{2}{|c|}{ Sawah } & \multicolumn{2}{|c|}{ Tegal } \\
\hline & & $\mathrm{PC}$ & $\mathrm{RC}$ & $\mathrm{PC}$ & $\mathrm{RC}$ \\
\hline 1. & Produksi Tebu (ton/ha) & 111,7 & 111,7 & 70 & 70 \\
\hline 2. & Rendemen $(\%)$ & 6,74 & 6,74 & 7,46 & 7,46 \\
\hline 3. & Bagi Hasil Gula Tani (66\%) & 4,97 & 4,97 & 3,45 & 3,45 \\
\hline 4. & Bagi Hasil Tetes (3\% tebu) & 3,35 & 3,35 & 2,1 & 2,1 \\
\hline 5. & Harga Gula ( $\mathrm{Rp},-/$ ton $)$ & 10.500 .000 & 10.500 .000 & 10.500 .000 & 10.500 .000 \\
\hline 6. & Harga Tetes (Rp ,-/ton) & 1.800 .000 & 1.800 .000 & 1.800 .000 & 1.800 .000 \\
\hline 7. & Biaya (Rp) & 53.019 .269 & 43.924 .269 & 38.730 .543 & 29.635 .543 \\
\hline \multirow[t]{4}{*}{8.} & Pendapatan & & & & \\
\hline & Gula Tani (Rp) & 52.173 .059 & 52.173 .059 & 36.188 .460 & 36.188 .460 \\
\hline & Tetes Tani (Rp) & 6.031 .800 & 6.031 .800 & 3.780 .000 & 3.780 .000 \\
\hline & Jumlah Pendapatan (Rp) & 58.204 .859 & 58.204 .859 & 39.968 .460 & 39.968 .460 \\
\hline 9. & Hasil Usahatani (Rp) & 5.185 .590 & 14.280 .590 & 1.237 .917 & 10.332 .917 \\
\hline 10. & Persentase Usaha (\%) & 9,78 & 32,51 & 3,2 & 34,87 \\
\hline
\end{tabular}

Sumber Analisis Data Primer, 2018

Tabel 5 menunjukkan persentase SHU yang sama dengan di desa sampel wilayah Barat dan Timur. Secara ekonomi usahatani tebu desa sampel wilayah Selatan memiliki persentase SHU positif disemua kategori (PC dan RC di lahan sawah serta PC dan RC di lahan tegalan), yang berarti usahatani tebu di desa sampel wilayah Selatan juga mempunyai prospek yang menguntungkan baik di lahan sawah maupun tegalan pada PC maupun RC. 
Namun jika dibandingkan antar kategori maka persentase SHU tertinggi diperoleh pada kategori RC di lahan tegal yaitu 34,87\%, sedangkan terendah adalah persentase SHU pada kategori PC di lahan tegal yaitu 3,2\%. Hal ini disebabkan biaya yang dibutuhkan pada RC lebih rendah daripada PC. Hal ini disebabkan pada PC lahan tegal dibutuhkan biaya bibit, pengolahan lahan, dan pengairan yang sangat besar karena iklim dan lahan yang kering. Kisaran persentase SHU usahatani tebu di desa sampel wilayah Selatan adalah 3,2 $34,87 \%$ dengan nilai SHU antara Rp 1,2 juta hingga Rp 10,3 juta per hektar per musim tanam. Adanya persaingan antara tanaman tebu dan padi, mendorong terjadinya pergeseran areal pertanaman tebu rakyat dari lahan sawah ke lahan kering. Daya saing usahatani tebu terhadap komoditas alternatif pada lahan sawah dipengaruhi oleh produktivitas hablur, serta perbandingan harga gula dan harga dasar gabah. Sedangkan pada lahan kering komoditas tebu memiliki daya saing lebih tinggi (Malian dan Syam, 1996).

3. Analisis Daya Saing Usahatani Tebu terhadap Non-Tebu

Menganalisa daya saing usahatani tebu terhadap non-tebu harus diasumsikan selama 1 tahun, dikarenakan tebu memiliki masa panen yang lebih lama dibandingkan usahatani non-tebu. Pada penelitian ini, disetiap wilayah kajian memiliki pola tanam usahatani non-tebu yang bervariasi dalam satu tahun.

Tabel 6. Daya Saing Usahatani Tebu terhadap Usahatani Non-Tebu di Wilayah Timur

\begin{tabular}{|c|c|c|c|c|c|c|c|}
\hline No. & Pola Tanam & $\begin{array}{l}\text { Biaya } \\
\text { (Rp) }\end{array}$ & $\begin{array}{l}\text { Pendapatan } \\
\text { (Rp) }\end{array}$ & $\begin{array}{l}\text { SHU } \\
\text { (Rp) }\end{array}$ & $\begin{array}{l}\text { Rendemen } \\
(\%)\end{array}$ & $\begin{array}{c}\text { SHU } \\
\text { daya saing } \\
(\mathrm{Rp})\end{array}$ & $\begin{array}{c}\text { Rendemen } \\
\text { daya saing } \\
(\%)\end{array}$ \\
\hline 1. & $\begin{array}{l}\text { Padi//Jagung// } \\
\text { Jagung }\end{array}$ & 34.724 .175 & 57.820 .000 & 23.095 .825 & & & \\
\hline 2. & Padi//Padi// Jagung & 35.189 .625 & 63.400 .000 & 28.210 .375 & & & \\
\hline 3. & $\begin{array}{l}\text { Kedelai//Bawang } \\
\text { Merah//Bawang } \\
\text { Merah } \\
\text { Tebu }\end{array}$ & 54.091 .175 & 58.850 .000 & 5.317 .075 & & & \\
\hline 4. & $\begin{array}{l}\text { Tebu } \\
\text { PC Sawah }\end{array}$ & 48.243 .895 & 57.383 .154 & 9.139 .259 & 7,26 & 28.210 .375 & 9,93 \\
\hline & RC Sawah & 39.301 .224 & 50.773 .982 & 11.472 .759 & 7,78 & 28.210 .375 & 10,6 \\
\hline
\end{tabular}

Sumber: Data Primer Diolah, 2018

Pola usahatani yang memiliki SHU tertiggi adalah padi // padi // jagung. Berdasarkan Tabel 6, maka SHU usahatani tebu dibandingkan non-tebu dalam masa satu tahun (satu okupasi) lebih tinggi dari pada SHU padi // padi // jagung. Atau dengan kata lain daya saing tebu di desa sampel wilayah timur adalah kuat. Khusus untuk PC sawah, untuk mampu bersaing dengan pola tanam non-tebu yang ada, maka usahatani tebu di desa sampel wilayah timur harus dapat mencapai rendemen $9,93 \%$, pada harga gula Rp $10.500,-/ \mathrm{kg}$ sesuai kondisi pada tahun giling 2017. Usahatani RC sawah dapat bersaing pada rendemen $10,6 \%$.

Tabel 7. Daya Saing Usahatani Tebu terhadap Usahatani Non-Tebu di Wilayah Barat

\begin{tabular}{|c|c|c|c|c|c|c|c|}
\hline No. & Pola Tanam & $\begin{array}{l}\text { Biaya } \\
(\mathrm{Rp})\end{array}$ & $\begin{array}{l}\text { Pendapatan } \\
\text { (Rp) }\end{array}$ & $\begin{array}{l}\text { SHU } \\
\text { (Rp) }\end{array}$ & $\begin{array}{c}\text { Rendemen } \\
(\%)\end{array}$ & $\begin{array}{c}\text { SHU } \\
\text { daya saing } \\
\text { (Rp) }\end{array}$ & $\begin{array}{c}\text { Rendemen } \\
\text { daya saing } \\
(\%)\end{array}$ \\
\hline 1. & Padi//Padi// Jagung & 31.302 .522 & 64.536 .000 & 33.233 .478 & & & \\
\hline 2. & $\begin{array}{l}\text { Jagung// Jagung// } \\
\text { Jagung }\end{array}$ & 28.535 .917 & 44.000 .800 & 15.464 .883 & & & \\
\hline 3. & Tebu & & & & & & \\
\hline & PC Sawah & 52.749 .153 & 58.000 .199 & 5.251 .046 & $7,05 \%$ & 33.233 .478 & $10,83 \%$ \\
\hline & RC Sawah & 34.990 .146 & 41.164 .888 & 6.174 .741 & $7,78 \%$ & 33.233 .478 & $13,41 \%$ \\
\hline & PC Tegal & 38.998 .150 & 44.977.997 & 5.979 .847 & $8,44 \%$ & 33.233 .478 & $14,03 \%$ \\
\hline & RC Tegal & 29.903 .150 & 44.977.997 & 15.074 .847 & $8,44 \%$ & 33.233 .478 & $12,16 \%$ \\
\hline
\end{tabular}

Sumber: Data Primer Diolah, 2018 
Pola tanam non-tebu yang dominan di desa sampel bagian Barat adalah Padi // Padi // Jagung (Musim Hujan // Musim Kering I // Musim Kering II). Berdasarkan Tabel 7, SHU usahatani tebu dibandingkan dengan non-tebu dalam masa satu tahun (satu okupasi) lebih tinggi SHU non-tebu. Untuk mampu bersaing dengan pola tanam tersebut maka usahatani tebu di desa sampel wilayah Barat harus dapat mencapai rendemen PC sawah 10,83\% dan RC Sawah $13,41 \%$ pada harga gula Rp $10.500,-/ \mathrm{kg}$ sesuai kondisi pada tahun giling 2017. Selanjutnya usahatani tebu RC sawah untuk dapat bersaing harus mencapai rendemen $14,03 \%$ dan RC tegal harus mencapai rendemen $12,16 \%$.

Tabel 8. Daya Saing Usahatani Tebu terhadap Usahatani Non-Tebu di Wilayah Selatan

\begin{tabular}{|c|c|c|c|c|c|c|c|}
\hline No. & Pola Tanam & $\begin{array}{c}\text { Biaya } \\
(\mathrm{Rp})\end{array}$ & $\begin{array}{c}\text { Pendapatan } \\
\text { (Rp) }\end{array}$ & $\begin{array}{l}\text { SHU } \\
(\mathrm{Rp})\end{array}$ & $\begin{array}{c}\text { Rendemen } \\
(\%)\end{array}$ & $\begin{array}{c}\text { SHU } \\
\text { daya saing } \\
(\mathrm{Rp})\end{array}$ & $\begin{array}{c}\text { Rendemen } \\
\text { daya saing } \\
(\%)\end{array}$ \\
\hline 1. & Padi// Padi// Jagung & 33.757 .311 & 65.064 .000 & 31.306 .689 & & & \\
\hline 2. & $\begin{array}{l}\text { Jagung// Jagung// } \\
\text { Jagung }\end{array}$ & 37.960 .033 & 53.998 .400 & 16.038 .367 & & & \\
\hline 3. & $\begin{array}{l}\text { Padi// Jagung// } \\
\text { Jagung }\end{array}$ & 33.757 .311 & 65.064 .000 & 31.306 .689 & & & \\
\hline 4. & Tebu & & & & & & \\
\hline & PC Sawah & 53.019 .269 & 58.204 .859 & 5.185 .590 & 6,74 & 16.038 .367 & 8,14 \\
\hline & RC Sawah & 43.924 .269 & 58.204 .859 & 14.280 .590 & 6,74 & 16.038 .367 & 6,97 \\
\hline & PC Tegal & 38.730 .543 & 39.968 .460 & 1.237 .917 & 7,46 & 16.038 .367 & 10,51 \\
\hline & RC Tegal & 29.635 .543 & 39.968 .460 & 10.332 .917 & 7,46 & 16.038 .367 & 8,64 \\
\hline
\end{tabular}

Sumber: Data Primer Diolah, 2018

Pola tanam non-tebu yang dominan di desa sampel bagian Selatan adalah jagung // jagung // jagung. Berdasarkan Tabel 8, SHU usahatani tebu dibandingkan non-tebu dalam masa satu tahun (satu okupasi) lebih tinggi SHU. Untuk mampu bersaing dengan pola tanam tersebut maka usahatani tebu di desa sampel wilayah selatan harus dapat mencapai rendemen PC sawah $8,14 \%$ dan RC Sawah 6,97\%, pada harga gula $\mathrm{Rp} 10.500,-/ \mathrm{kg}$ sesuai kondisi pada tahun giling 2017. Selanjutnya usahatani tebu PC tegal untuk dapat bersaing harus mencapai rendemen $10,51 \%$ dan $\mathrm{RC}$ tegal harus mencapai rendemen $8,64 \%$.

\section{KESIMPULAN DAN SARAN}

\section{Kesimpulan}

Kinerja PG Wonolangan tahun 2013 - 2017 masih sangat fluktuatif, disebabkan ada berbagai faktor yang diduga mempengaruhi. Salah satu faktor tersebut adalah perubahan iklim yang ekstrem (el nino). Oleh sebab itu, untuk menjaga kestabilan pasok tebu musim giling 2018 maka PG Wonolangan merancang strategi baik secara on farm maupun off farm. Hasil analisis daya saing usahatani tebu terhadap komoditas non-tebu didapatkan bahwa seluruh wilayah di PG Wonolangan baik Timur, Selatan, dan Barat, secara persentase usaha belum mampu bersaing atau mengalami persaingan yang sangat kuat dengan tanaman non-tebu. Hal ini dilihat dari SHU yang diperoleh petani masih lebih rendah dibanding non-tebu. Hanya 1 wilayah yang memiliki SHU dengan selisih sedikit dengan komoditas non-tebu yaitu wilayah selatan dengan kategori RC sawah.

\section{Saran}

Strategi on farm yang diperlukan untuk mencapai kinerja PG Wonolangan yang stabil adalah perbaikan dari sisi on farm yaitu pembinaan kepada petani tebu agar dapat menghasilkan kualitas budidaya tebu yang optimum, pembinaan yang dilakukan dapat berupa pemberian fasilitas kebutuhan sarana produksi (kredit, pupuk bersubsidi, herbisida, dan lain-lain), dan secara intensif melakukan pengawalan sejak awal pengolahan lahan, pemilihan varietas, penyediaan benih, tanam, perawatan, sampai kepada manajemen TMA (Tebang, Muat, Angkut). Sisi off farm, manajemen PG Wonolangan bisa melakukan penerapan sistem analisis rendemen individu (ARI) yang berguna untuk memberikan apresiasi kepada petani, meningkatkan kualitas tebangan, dan penentuan rendemen secara transparan, adil, dan akurat. Dari seluruh perbaikan baik dari segi 
on farm maupun off farm tentunya akan berdampak pada peningkatan SHU disisi petani sehingga bisa berdaya saing dengan komoditas non-tebu.

\section{DAFTAR PUSTAKA}

Ahadis. H., Hasyim. A.I., \& Kasymir, E. 2012. Analisis Daya Saing Dan Strategi Peningkatan Produksi Gula Melalui Program Akselerasi Di Kabupaten Lampung Utara. Bandar Lampung: Magister Ekonomi Pertanian/Agribisnis Fakultas Pertanian, Universitas Lampung.

Ahmad, Z.T., Made S.S., \& Lucia E.W. 2016. Meningkatkan Daya Saing Pabrik Gula di Indonesia Era Masyarakat Ekonomi Asean (MEA).Journal Riset Ekonomi dan Manajemen. 16(2), 225-236.

Ariani, M., Askin, A., \& Hestina, J. 2004. Analisis Daya Saing Usahatani Tebu di Propinsi Jawa Timur. Bogor: Pusat Penelitian dan Pengembangan Sosial Ekonomi Pertanian, Balitbangtan, Departemen Pertanian.

Badan Pusat Statistik [BPS] Lumajang. 2017. Kabupaten Lumajang dalam Angka. Lumajang: Badan Pusat Statistik.

Badan Pusat Statistik [BPS] Probolingo. 2017. Kabupaten Probolinggo dalam Angka. Probolinggo: Badan Pusat Statistik.

Bantacut, T. 2010. Swasembada Gula: Prospek dan Strategi Pencapaiannya. Jurnal Pangan. 19(3), 245-256.

Instruksi Presiden Nomer 5. 1998. Penghentian Pelaksanaan Instruksi Presiden Nomor 5 Tahun 1997 Tentang Program Pengembangan Tebu Rakyat. Jakarta: Biro Hukum dan Perundang-undangan Republik Indonesia.

Instruksi Presiden Nomer 9. 1975. Intensifikasi Tebu Rakyat. Jakarta.

Malian, A.H., \& Syam, A. 1996. Daya Saing Usahatani Tebu di Jawa Timur. FAE Pusat Penelitian Sosial Ekonomi Pertanian. 14(1), 111.

Maulidiah, F. 2012, Perkembangan Kemitraan Petani Tebu dengan PG Krebet Baru, Perilaku Ekonomi Petani Tebu. Prodi Pendidikan Sejarah, Jurusan Sejarah Fakultas Ilmu Sosial Universitas Negeri Malang, Malang.
Moleong. 2011. Metode Penelitian Kualitatif (Edisi Revisi). Bandung: PT. Remaja Rosdakarya

Nurjayanti, E.D., \& Syaifun, N. 2014. Analisis Kelayakan Usahatani Tebu (Studi Kasus Petani Tebu Mitra PG. Pakis Baru di Kecamatan Tayu Kabupatn Pati). MEDIAGRO. 10(1), 60-68.

Prawiro, M.K. 2011. Usahatani Tebu (Sacharum officinarum) Antara Sistem Bongkar Ratoon dengan Sistem Rawat Ratoon di wilayah Kecamatan Prambon. [Skripsi] Surabaya: Fakultas Pertanian Universitas Pembangunan Nasional "Veteran" Jawa Timur.

Prihatiningrum, A.E. 2010. Uji Produktivitas Model PKP 240 Pada Tanaman Tebu Varietas BL di Lahan Kering Mumbul Kabupaten Jember. Jurnal Agrofish. 7(1), 28-36.

Priyadi, U. 1997. Pelaksanaan Usahatani Tebu Pasca Pencabutan Inpres Nomor 5 Tahun 1997 (Program Pengembangan TRI) di Propinsi Daerah Istimewa Yogyakarta. UNISIA. 33(73), 17-36.

Singarimbun, E. 1989. Metode Penelitian Survai (Edisi Revisi). Jakarta: Lembaga Peneitian, Pendidikan dan Penerangan Ekonomi dan Sosial.

Soentoro, N.I., \& Ali, A.M.S. 1999. Usaha Tani Dan Tebu Rakyat Intensifikasi di Jawa. Dalam Ekonomi Gula di Indonesia. Bogor: Penerbit Institut Pertanian.

Sugiyono. 2005. Memahami Penelitian Kualitatif. Bandung: Alfabeta.

Sutiarso, E. 2018.Analisis Daya Saing Agribisnis Bawang Merah di Kabupaten Probolinggo. Jember: Universitas Muhamadiyah Jember.

Sutrisno, B. 2009. Analisis Faktor-Faktor yang Mempengaruhi Tingkat Pendapatan Petani Tebu Pabrik Gula Mojo Sragen. Jurnal Ekonomi Manajemen Sumberdaya. 10(2), 155164.

Tunjungsari, R. 2014. Analisis Produksi Tebu di Jawa Tengah. JEJAK Journal of Economics and Policy. 7(2), 100-102. doi: 10.15294/jejak.v7i1.359 